\title{
EDITORIAL
}

\section{O NOVO DETALHE ARQUITETÔNICO}

\section{THE NEW ARCHITECTURAL DETAIL}

Gabriela Celani

Professora Associada, Faculdade de Engenharia Civil, Arquitetura e Urbanismo (FEC) da Universidade Estadual de Campinas (Unicamp)

José M. P. Duarte

Presidente da Faculdade de Arquitectura (FA) da Universidade de Lisboa (ULisboa)

A ideia de fazer uma chamada específica da revista PARC com o tema do detalhamento arquitetônico surgiu a partir de dois acontecimentos no primeiro semestre de 2013. O primeiro foi o oferecimento da disciplina de Prototipagem e Fabricação Digital, em que se procurou explorar a relação entre o processo de detalhamento e o uso das novas tecnologias CAD/CAM, no programa de pós-graduação da Faculdade de Engenharia Civil, Arquitetura e Urbanismo (FEC) da Unicamp em Arquitetura, Tecnologia e Cidade (ATC). O segundo acontecimento foi a realização do congresso Sustainable Intelligent Manufacturing (SIM), de 26 a 29 de junho, na Faculdade de Arquitectura (FA) da Universidade de Lisboa, reunindo designers, arquitetos e representantes da indústria que utiliza alta tecnologia.

A disciplina da FEC começou com uma revisão dos conceitos de detalhamento arquitetônico, em que foi possível observar como a literatura dessa área se encontra desatualizada com relação aos novos meios de produção. Foi necessário fazer a intersecção entre obras de teoria e de tecnologia da arquitetura com livros da área de manufatura e montagem de produtos na indústria. A disciplina propôs o desenvolvimento de um sistema de proteção solar para um edifício com fachada curva, com o uso da fabricação digital. $\mathrm{O}$ trabalho desenvolvido pela maioria das equipes revelou que o projeto para o edifício produzido com tecnologias CAD/CAM deve levar esse fato em consideração desde o início do processo.

No congresso SIM, sob a curadoria de José Duarte, Gabriela Celani fez uma apresentação sobre as conclusões tiradas a partir dessa experiência na Unicamp e sobre relatos recentes de obras projetadas e produzidas com o auxílio das tecnologias digitais. Um bom exemplo é o "Tree-Structure Canopy" de Agkathidis (2013), publicado na revista International Journal of Design Computing, cujos elementos estruturais tiveram seu comprimento limitado pelo tamanho dos equipamentos da empresa que os fabricou. Daí surgiu o tema para a revista. A chamada se estendeu por vários meses, e não foi nada fácil localizar pesquisadores que já tivessem algum material produzido sobre este assunto tão novo. Nossos pareceristas realizaram um trabalho criterioso para garantir que este número não fugisse do assunto proposto.

Na categoria Jovem Pesquisador, Etiene do Amaral Arcari, arquiteta e mestranda da Universidade Federal de Santa Catarina (UFSC), escreve sobre a criação de bibliotecas digitais como auxílio ao desenvolvimento de detalhes arquitetônicos. Ora, em um mundo digital, faz muito mais sentido disponibilizar na Internet arquivos contendo detalhes típicos, que podem ser posteriormente alterados, do que distribuí-los por meio de livros impressos. Uma das principais vantagens, segundo Etiene, é que esses detalhes digitais podem levar consigo certas configurações que os deixam prontos para serm inseridos em um Building Information Model. O passo seguinte, conclui Etiene, será disponibilizar arquivos de detalhes prontos para serem enviados a equipamentos de controle numérico.

Em seguida, Chor-Kheng Lim, da YuanZe University, Taiwan, discute a introdução do CAM na formação do arquiteto, e como ele poderia ser integrado às disciplinas de projeto, algo que já começou a ser implementado nas escolas de arquitetura do MIT, Harvard, Columbia, Architectural Association (AA), e Swiss Federal Institute of Technology Zurich (ETH). O texto de Lim é particularmente interessante para educadores brasileiros porque leva em consideração contextos em que as tecnologias digitais ainda não são tratadas com a mesma naturalidade que nos países mais desenvolvidos.

Maycon Sedrez, arquiteto e doutorando da FEC, e Rafael de Moraes Meneghel, tecnólogo em Tecnologia da Informação, apresentam o trabalho desenvolvido para a disciplina de Fabricação Digital acima citada, descrevendo em detalhe o processo de projeto e a produção de seus protótipos. O sistema adotado para a produção dos elementos de fachada, com chapas recortadas e perfuradas em uma fresadora de controle numérico, acaba criando a necessidade de 
desenvolvimento de um algoritmo que permite controlar o posicionamento dos furos a uma determinada distância dos recortes. Esse fato mostra como o processo de detalhamento na era digital requer mais que a simples habilidade de desenho. O desenvolvimento de algoritmos permite que os detalhes sejam literalmente "programados" para atender às diferentes situações do projeto, sem resultar em um trabalho de desenho repetitivo por parte dos projetistas.

O último artigo é de Andre Chaszar, renomado pesquisador e consultor na área de design computing, uma nova área de atuação para arquitetos que envolve a resolução de problemas no projeto e produção de formas complexas. $\mathrm{O}$ cuidadoso relato de Chaszar sobre o processo de detalhamento e fabricação digital de paineis compostos curvos dá uma boa ideia do nível de sofisticação e da complexidade com que a futura geração de arquitetos terá de se acostumar a lidar.

O número se encerra com a transcrição de uma conversa informal entre Branko Kolarevic e os pesquisadores do Laboratório de Automação e Prototipagem para Arquitetura e Construção (LAPAC) da FEC-Unicamp, realizada em 18 de dezembro de 2013, por video-conferência. Kolarevic é conhecido por sua trilogia sobre as novas tecnologias na arquitetura: Architecture in the Digital Age: Design and Manufacturing (de 2005), Performative Architecture: Beyond Instrumentality (de 2007, com Ali Malkawi), e Manufacturing Material Effects: Rethinking Design and Making in Architecture (de 2008, com Kevin Klinger). Seus livros foram os principais responsáveis pela difusão das aplicações da technologia CAM na arquitetura, de uma maneira crítica e vinculada à teoria da arquitetura e aos métodos de projeto.

Embora não tenha sido nada fácil encontrar pesquisadores dispostos a discorrer sobre o impacto das novas tecnologias no detalhamento arquitetônico, é possível prever que esse assunto será muito discutido nos próximos anos. Um exemplo disto é o artigo publicado em 2 de dezembro de 2013 na revista Dezeen (http://www.dezeen.com/2013/12/02/firstarchitectural-application-of-3d-printing-adrian-priestman-6-bevis-marks/), que descreve um revestimento para nós de estruturas metálicas produzido por sinterização seletiva a laser (SLS). Segundo seu idealizador, o arquiteto inglês Adrian Priestman, esta seria a primeira verdadeira aplicação da tecnologia de impressão 3D na arquitetura, uma vez que seu produto foi o primeiro a ser aprovado pelas autoridades competentes para o uso na construção civil. Outro fato que demonstra esse interesse é o lançamento do próximo número especial da revista britênica Architectural Design, previsto para janeiro de 2014, que será dedicado interiamente ao impacto da fabricação digital na construção. O número, intitulado High Definition: Zero Tolerance in Design and Production, é editado por Bob Sheil e incluirá um artigo de Kolarevic, que é mencionado por ele na entrevista deste número da PARC.

Aproveitem a leitura e enviem mensagens contando-nos o que acharam dos artigos e da entrevista!

Gabi e José

celani@fec.unicamp.br

\section{Referências}

AGKATHIDIS, A. and BROWN, A. Tree-Structure Canopy: A Case Study in Design and Fabrication of Complex Steel Structures using Digital Tools. IJAC, v.1, n.11, p.87-104, 2013. Disponível em: http://www.metapress.com/content/x77626t08lw4867l/

DEZEEN. British architect claims "first architectural application" of 3D printing. Dezeen, 2/dezembro, 2013. Disponível em: http://www.dezeen.com/2013/12/02/first-architectural-application-of-3d-printing-adrian-priestman-6-bevis-marks/. Acesso em: 16/12/2013.

SHEIL, B. (Ed.) High Definition: Zero Tolerance in Design and Production (Architectural Design). London: Wiley, 2014 (in the press). 